\title{
Prevalence of cystic fibrosis mutations in the Grampian region of Scotland
}

\author{
Zofia H Miedzybrodzka, John C S Dean, George Russell, James A R Friend, \\ Kevin F Kelly, Neva E Haites
}

\begin{abstract}
We have identified all known sufferers of cystic fibrosis (CF) alive in the Grampian region, north east Scotland, on 1 January 1989. DNA samples were obtained for a prevalence study of the common mutations with near to complete ascertainment. A relatively high prevalence of the $\Delta F 508$ mutation was found $(82 \%)$, with one of four mutations being present on $92 \%$ of CF chromosomes. The high prevalence of these four easily detectable mutations in Grampian has local implications for genetic counselling, the efficacy of population carrier screening, and the usefulness of mutation analysis in cases where the diagnosis of CF is in doubt.

( $\mathcal{F}$ Med Genet 1993;30:316-17)
\end{abstract}

We have identified all known cystic fibrosis (CF) sufferers alive in the Grampian region, Orkney, and Shetland (population 545000 ) on 1 January 1989 as part of a population study of north east Scotland.

Patients were identified from all possible sources including clinicians, local registers, and national computerised records. CF diagnosis required relevant clinical features and three positive sweat tests. DNA samples were obtained and tested for the mutations listed in the table using standard methods. ${ }^{1-3}$

A life table of age at diagnosis was constructed and used to estimate the proportion of cases alive on 1.1.89 whose diagnosis had not been made by $1.7 .92(17 \%)$. Results of mutation analysis are presented in the table. The proportion of $\triangle F 508 \mathrm{CF}$ chromosomes found $(82 \%)$ was significantly greater than that reported previously for Scotland ${ }^{1}(71 \%, 95 \%$ confidence intervals 0.02 and 0.18 ).

The $\Delta$ F508 frequency among CF chromosomes of Grampian origin (grandparents) was not significantly different from that among chromosomes from outside Grampian (50/64 v $21 / 24, \chi^{2}=0.98$ ).

Frequency of CF mutations in Grampian on 1.1.1989.

\begin{tabular}{lcc}
\hline Mutation & $\begin{array}{c}\text { No of CF } \\
\text { chromosomes }\end{array}$ & Proportion (\%) \\
\hline AF508 & 96 & $82 \cdot 1$ \\
G551D & 8 & $6 \cdot 8$ \\
G542X & 2 & $1 \cdot 7$ \\
A1507 & 1 & 0.85 \\
1717-1G-A & 1 & 0.85 \\
621 +1G-T & 1 & 0.85 \\
R553X & 1 & 0.85 \\
R550T & 0 & - \\
R117H & 0 & $6 \cdot 0$ \\
No mutation identified & 7 & $100 \cdot 0$ \\
Total & 117 & \\
\hline
\end{tabular}

The calculated point prevalence, adjusting for cases in whom a diagnosis has not yet been made, was much higher (1/7100) than that reported for Britain $\left(1 / 11400^{4}\right)$, as was the calculated incidence $(1 / 2260 v 1 / 2500)$. These findings may reflect a higher gene frequency in Grampian, longer survival, or merely better ascertainment.

The proportion of CF chromosomes carrying the $\Delta F 508$ mutation in Grampian is significantly higher $(82 \%)$ than that reported previously for a Scottish population $(71 \%) .{ }^{1}$ That population was largely from south east Scotland, so both these frequencies fit the north west-south east cline in $\Delta \mathrm{F} 508$ frequency across Europe. ${ }^{5}$ Alternatively, our findings may reflect a founder effect, as has been shown in Brittany $(80 \%)^{6}$ and the Basque country $(87 \%))^{7}$

However, the origin of chromosomes in our study has no effect on $\Delta \mathrm{F} 508$ frequency so our findings may reflect virtually complete ascertainment and careful exclusion criteria. All the CF chromosomes carrying G551D were of Grampian origin, which is in keeping with the hypothesis that it is a Celtic mutation. ${ }^{6}$

All CF patients in Grampian have at least one identifiable CF mutation, so we predict only 1 in 277 patients would have no detectable mutations (Hardy-Weinberg). This may be helpful in cases where the diagnosis of CF is in doubt.

Testing for four common mutations simultaneously $(\Delta \mathrm{F} 508, \mathrm{G} 551 \mathrm{D}, \mathrm{G} 542 \mathrm{X}$, and $621+1 \mathrm{G}-\mathrm{T})^{2}$ can detect $92 \%$ of Grampian carriers, making carrier screening more efficient than might be expected from other studies $\left(84 \%\right.$ Scottish study, ${ }^{1} 83 \%$ Welsh study $\left.{ }^{8}\right)$. Eighty-three percent of carrier couples are identified in contrast to $71 \%$ calculated from the Scottish study ${ }^{1}$ and $69 \%$ from the Welsh study. ${ }^{8}$ When the partner of a carrier tests negative for the above mutations, the couple's residual risk of having an affected child is of the order of $1 / 1200$ compared to $1 / 520$.

Local knowledge of the prevalence of CF mutations is essential for good genetic counselling for CF families and before considering any population for screening. Any cost-benefit analysis of screening produced by studies from other areas should be considered in the context of the local prevalence of mutations.

Z Miedzybrodzka is currently funded by the Wellcome Trust and previously by a Scottish Hospitals Endowments Research Trust Cruden Scholarship. This work was funded by Grampian Health Board and the Scottish Hos- 
pitals Endowments Research Trust. We are grateful to Ms Mona Abdulla for statistical help, Drs Tony Shrimpton and Steve Little for helpful advice, the European Community Concerted Action on Cystic Fibrosis for provision of control DNA and some oligonucleotides, Cellmark Diagnostics for provision of ARMS kits, and Dr Joe Legge for permission to enrol his patient in the study. We would also like to thank Elspeth Bruford, Mark Davidson, Gail Rettie, Alasdair Williamson, and Zhikang Yin for technical help.

1 Shrimpton AE, McIntosh I, Brock DJ. The incidence of different cystic fibrosis mutations in the Scottish population: effects on prenatal diagnosis and genetic counselling.

2 Ferrie RM, Schwarz MJ, Robertson N, et al. Development, multiplexing and application of ARMS tests for common mutations in the CFTR gene. Am $\mathcal{f}$ Hum Genet mutations in $1992 ; 51: 251-62$.

3 Miedzybrodzka ZH, Kelly KF, Davidson M, et al. Prenatal diagnosis for the cystic fibrosis mutation 1717-1,G-A using ARMS. Prenat Diagn 1992;12:845-9.

4 British Paediatric Association Working Party on Cystic Fibrosis. Cystic fibrosis in the United Kingdom 1977-85: an improving picture. $B M \mathcal{F}$ 1988;297:1599-602.

5 European Working Group on Cystic Fibrosis Genetics. Gradient of distribution in Europe of the major CF mutation and of its associated haplotype. Hum Genet 1990;85:436-40.

6 Ferec C, Guillermit H, Chaventre A. Les mutations du gene de la mucoviscidose dans la population Bretonne. (Gene mutations of cystic fibrosis in Brittany population.) Pathol Biol (Paris) 1991;39:577-80.

7 Casals T, Vazquez C, Lazaro C, et al. Cystic fibrosis in the Basque country: high frequency of mutation delta F508 in patients of Basque origin. Am 7 Hum Genet 1992;50:40410.

8 Cheadle J, Myring J, Al-Jader L, et al. Mutation analysis of 184 cystic fibrosis families in Wales. $\mathcal{F}$ Med Genet 1992;29:642-6. 